\title{
Cost analysis of Greenlight photoselective vaporization of the prostate compared to transurethral resection of the prostate for benign prostatic hyperplasia
}

\author{
Lisa Masucci $^{1,2}$; Aysegul Erman ${ }^{1,3}$; Murray D. Krahn ${ }^{1,2,3}$; Dean Elterman ${ }^{4,5}$ \\ ${ }^{1}$ Toronto Health Economics and Technology Assessment Collaborative (THETA), University of Toronto; \\ ${ }^{2}$ Institute of Health Policy, Management, and Evaluation; ${ }^{3}$ Leslie Dan Faculty of Pharmacy, University of \\ Toronto; ${ }^{4}$ Division of Urology, University of Toronto; ${ }^{5}$ Krembil Research Institute, Toronto Western \\ Hospital, University Health Network; Toronto, ON, Canada
}

Cite as: Can Urol Assoc J 2018 June 19; Epub ahead of print. http://dx.doi.org/10.5489/cuaj.5267

Funding: This research was funded through an unrestricted educational grant from Boston Scientific.

Published online June 19, 2018

$* * *$

\section{Abstract}

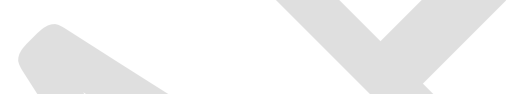

Introduction: Benign prostatic hyperplasia (BPH) is a non-cancerous enlargement of the prostate gland, which results in the development of lower urinary tract symptoms that can interfere with a patient's daily activities and negatively impact their quality of life. The gold standard treatment for moderate to severe BPH has been transurethral resection of the prostate (TURP), however, this procedure is associated with prolonged hospitalizations and increased complications. An alternative to TURP is Greenlight photoselective vaporization of the prostate (PVP), which is associated with better perioperative safety. The objectives of the research were to 1) assess the cost of Greenlight PVP compared to TURP and bipolar TURP; and 2) assess the predictors of total cost.

Methods: We conducted a descriptive costing study from the hospital perspective. We evaluated perioperative costs of patients who underwent each procedure from 2013-2015 at a tertiary academic medical centre. A multiple linear regression was performed to identify predictors of total cost. The variables included in regression analysis were patient age, type of procedure, Charlson Comorbidity Index, and distance to clinic.

Results: A total of 202 patients received one of the three procedures over the study period. The total cost of Greenlight PVP was \$3836 per patient compared to \$4963 for TURP and \$4978 for bipolar TURP. The linear regression showed that the Charlson Comorbidity Index and type of procedure were independent predictors of total cost. 
Conclusions: The procedure costs and readmission rates are lower for Greenlight PVP compared to TURP and bipolar TURP, making it a preferable option for hospitals.

\section{Introduction}

Benign prostatic hyperplasia (BPH) is a non-cancerous enlargement of the prostate gland, which results in the development of lower urinary tract symptoms (LUTS) that can interfere with a patient's daily activities and negatively impact their quality of life. ${ }^{1} \mathrm{BPH}$ affects up to $50 \%$ of men aged 50 years and older, with symptoms increasing with age. ${ }^{2}$

The gold standard surgical treatment for moderate to severe $\mathrm{BPH}$ has been transurethral resection of the prostate (TURP). During this procedure, the physician inserts a scope into the urethra and uses a electrified wire loop to cut the prostate tissue. A newer form of this procedure, using bipolar electricity, called bipolar plasma vaporization of the prostate, uses low temperature plasma energy to remove the prostate tissue. The main device used for this modality is the Olympus Plasma Button (Olympus Corporation, Tokyo, Japan). TURP, however, has been associated with prolonged hospitalization and increased rates of complications. ${ }^{3}$ These complications include blood transfusion and TURP syndrome. An alternative to TURP is photoselective vaporization of the prostate (PVP) with Greenlight laser (Boston Scientific, Marlborough, USA). Greenlight PVP is an outpatient procedure that has better perioperative safety, shorter hospitalization time, faster symptomatic improvement, and decreased morbidity compared to TURP.,

Studies have compared the cost of TURP to Greenlight $\mathrm{PVP}^{6-10}$ and have consistently found that Greenlight PVP is less costly. These cost-savings have been mainly due to patients being treated on an outpatient bases with Greenlight PVP. Only one cost analysis has found that Greenlight PVP is more costly than TURP. ${ }^{11}$ This study was from Australia and reported that Greenlight PVP costs \$79 (AUD) more than TURP per patient. ${ }^{11}$ This was due to the cost of equipment and training. ${ }^{11}$ When these costs were excluded from the analysis, Greenlight PVP was cost saving compared to TURP.

Two studies in Canada have compared the costs associated with Greenlight PVP to TURP. ${ }^{10}$ One study was a prospective non-randomized trial that followed patients up to 6 months following surgery. ${ }^{10}$ The study found that due to the outpatient nature of Greenlight PVP, treating subjects with Greenlight PVP instead of TURP decreased the total costs by almost $\$ 1,300$ (CAD) per patient. The other Canadian study was a costminimization analysis from the payer's perspective. This study found that PVP cost less than TURP even after accounting for start-up costs. ${ }^{6}$ Many hospitals and healthcare payers continue to modernize their BPH surgical equipment and considerations of cost should be taken into account.

The objective of our study was to compare the costs of Greenlight PVP versus TURP, and bipolar TURP from a hospital perspective as well as determine the predictors of total cost. 


\section{Methods}

Patient population

A retrospective analysis was conducted of perioperative hospital costs of patients who underwent Greenlight PVP, TURP, or bipolar TURP. Costs were based on surgeries conducted between September 2013 and September 30 ${ }^{\text {th }}, 2015$ at the Toronto Western Hospital, Toronto, Ontario.

The XPS Greenlight 180W system was used by all physicians. Greenlight PVP procedures were performed by three physicians trained to use the laser system. For this analysis, the first 10 cases of Greenlight PVP for each physician were excluded from the analysis due to the learning curve of using the new technology. In addition, patients presenting through the emergency department were also excluded.

Chart review and administrative databases

Data on patient age, Charlson Comorbidity Index, number of patients on anticoagulation therapy, patients on past medical therapy for BPH, and number of patients with a diagnosis of prostate cancer were captured through chart review. Distance to clinic was captured using patient postal codes from chart reviews. The type of procedure, length of stay, procedure costs and the number of readmissions at 30 and 60 days post-intervention were obtained from the Toronto Western Hospital administrative database.

Cost analysis

Costs were captured from the perspective of the hospital. For each patient, both direct and indirect hospital costs were obtained for each procedure. Variable direct costs included the cost of labor (medical personnel on fee for service), patient supplies, and drugs. The cost of the fibre for Greenlight PVP, resecting loop for TURP, and the Olympus plasma button as well as drug costs were included in the variable patient supply cost. Fixed direct costs included the cost of labor (medical personnel not paid through fee for service), equipment, building and grounds. Variable and fixed indirect costs pertained to hospital operating costs (i.e., functional centre costs classified as overhead). A cost per patient was calculated by dividing the total costs by the number of patients in each group. All costs are reported in 2015 Canadian dollars.

Statistical analysis

Data were captured in Excel ${ }^{\circledR} 2011$ and statistical analysis was conducted in STATA 14.1. Mean costs and the 95\% confidence intervals are presented. Multiple linear regression analysis was performed in order to identify predictors of total cost and obtain covariate-adjusted costs. The total cost included the cost of the procedure and readmissions at 60 days. The variables included in the regression analysis were the type of procedure, patient age, Charlson Comorbidity Index, and distance to the clinic. For 
type of procedure, Greenlight PVP was used as the reference category. Age and distance to the clinic were continuous variables.

\section{Results}

\section{Patient characteristics}

Two-hundred and twenty-two patients received a procedure for BPH between 2013-2015. After exclusion of the first ten cases of Greenlight PVP for each physician, two-hundred and two patients corresponding to two hundred and three visits involving Greenlight PVP $(\mathrm{N}=56)$, bipolar TURP $(\mathrm{n}=29)$ and TURP $(\mathrm{n}=118)$ were included in the analysis. No deaths were reported during the study period.

The general characteristics of patients and hospital data are presented in Table 1. On average patients were 71 years of age and approximately $90 \%$ had a previous history of BPH therapy. These characteristics were similar across all treatment groups. Overall, more patients undergoing Greenlight PVP (27\%) were on anti-coagulation therapy versus bipolar TURP (24\%) and TURP (15\%). The number that had retention at the time of surgery and the number that had a previous TURP were comparable across groups.

Substantially more patients were treated on an outpatient basis with Greenlight PVP (93\%) versus bipolar TURP (0\%) and TURP (6\%). On average, the inpatient length of stay was shorter for Greenlight PVP compared to TURP and bipolar TURP (1.03 vs. 1.67 days and 1.45 , respectively). The mean operating room times were 1 hour and 30 minutes for Greenlight PVP, 1 hour and 18 minutes for TURP, and 1 hour and 9 minutes for bipolar TURP. The majority of patients who underwent Greenlight PVP had one laser fibre used for the procedure (98\%).

\section{Total costs}

Table 2 reports the mean per patient cost for all cases (i.e., including both day surgery and inpatient cases) by type of procedure. In total, Greenlight PVP cost \$3,836, bipolar TURP \$4,978 and TURP \$4,963 per patient. Greenlight PVP was the least costly option, costing on average $\$ 1,127$ less than TURP and \$1,142 less than bipolar TURP.

Cost of day surgery and inpatient cases

With respect to type of procedure, a majority, 93\% of Greenlight PVP procedures were performed as day surgery, in contrast to approximately 6\% of TURP and none of the bipolar TURP procedures (Table 1). Therefore, savings in overall cost are mainly attributed to a reduced frequency of costlier inpatient hospitalizations with Greenlight PVP versus other procedures.

Tables 3 and 4 report the mean costs per patient for day surgery and inpatient cases respectively by type of procedure. For day surgery cases, there were 52 cases for Greenlight PVP and 7 cases for TURP. Out of the 7 TURP cases, 3 patients were 
undergoing revisions of a prior TURP procedure. Greenlight PVP cost \$3,713 and TURP cost \$2,672 per patient. On average, Greenlight PVP cost \$1,041 more than TURP for day surgery cases. This cost difference is mainly attributed to increased variable labor and patient supply cost for Greenlight PVP.

For inpatient cases (Table 4), on average, Greenlight PVP cost \$5,432, bipolar TURP \$4,978 and TURP \$5,109 per patient. Thus, for inpatient cases, Greenlight PVP cost \$344 more than TURP and \$475 more than bipolar TURP.

\section{Readmissions}

Greenlight PVP resulted in lower hospital readmission rates at 30 and 60 days compared to TURP (14\% vs. $19 \%$, and 0\% vs. 4\%, respectively) (Table 5). There were also lower readmission rates at 30 days compared to bipolar TURP (14\% vs. 28\%). The mean readmission cost per patient at 30 days was lower for Greenlight PVP versus TURP. At 60 days there were no readmissions for Greenlight PVP, no readmissions for bipolar TURP, and 4 readmissions for TURP. The mean per patient cost of readmissions at 60 days for TURP was $\$ 2,460$.

Predictors of total costs

Table 6 reports the results of the multiple linear regression analysis of total costs adjusting for the type of procedure, patient age, comorbidity, and distance from clinic. Based on the regression analysis, the type of procedure and Charlson Comorbidity Index were independent predictors of total costs $(\mathrm{P}<0.01)$. After adjusting for covariates, Greenlight PVP was associated with a decrease in costs of \$1,219 versus TURP and \$1,156 versus bipolar TURP. As well, after adjustment for covariates, those with a Charlson Comorbidity Index of 2 or more had a $\$ 769$ increase in costs.

\section{Discussion}

TURP has been the established gold standard procedure for BPH. Decisions regarding the introduction of a new technology such as Greenlight PVP often involve considerations of safety, value for money, patient values, and feasibility of adoption into the healthcare system.

In regards to patient safety, Greenlight PVP is a painless procedure that can be offered in an outpatient setting. Three literature reviews on the safety profiles of the two technologies found that adverse events (i.e., urinary retention and clot retention) were comparable or lower for Greenlight PVP compared to TURP. ${ }^{6,12,13}$ Our study found that readmissions to hospital after Greenlight PVP were less than that of TURP. TURP resulted in 15 more readmissions at 30 days and 4 more readmissions at 60 days. However, others have found that readmissions between the two treatments are comparable. ${ }^{6,10}$ One Canadian study has reported 0 readmissions and 3 readmissions for 
Greenlight PVP over a 6-month period. ${ }^{10}$ For Greenlight PVP compared to bipolar TURP the number of readmission at 30 and 60 days were comparable.

It has also been reported that there is no difference in health-related quality of life between Greenlight PVP and TURP. ${ }^{10,13}$ There are some discrepancies within the literature as to whether there is greater preservation of sexual function with Greenlight PVP compared to TURP. Although some have reported there is no difference in sexual function between Greenlight PVP and TURP ${ }^{5,10,14}$, others have reported there is a significantly lower retrograde ejaculation rate among those who received Greenlight PVP. $^{15}$

Given comparable patient safety and quality of life outcomes for both treatments, whether Greenlight PVP should be adopted, as an alternative to TURP may be a matter of cost. We found that Greenlight PVP cost \$1,142 less than bipolar TURP and \$1,127 less than TURP. The savings in costs are mainly attributed to costly inpatient hospitalizations associated with TURP. These results are consistent with a Canadian study that reported Greenlight PVP cost $\$ 1,300$ less per patient in comparison to TURP. ${ }^{10}$ Our study results are also similar to others studies that have found Greenlight PVP to be less costly than TURP. ${ }^{6,710,11}$ The reason for these findings has been that Greenlight PVP is provided on an outpatient basis and TURP requires inpatient postoperative care. While the bipolar TURP may be performed as outpatient surgery in certain highly selected patients, this has not been the case at our institution.

In addition to a cost analysis, we also conducted a multiple linear regression to determine the predictors of total cost. We found that both the type of procedure and the Charlson Comorbidity Index were statistically significant predictors of total cost.

Consistent with our costing results, Greenlight PVP was associated with lower costs compared to bipolar TURP and TURP. Those with a Charlson Comorbidity Index of 2 or greater had higher costs than those with a lower index. It could be that the comorbidities are associated with a greater length of stay in hospital or require more resources.

There are some strengths and limitations of this study that should be noted. First, this analysis was conducted from a hospital perspective and so costs incurred by the Ministry of Health and Long-Term Care, as well as patient out of pocket costs were not included. Second, we did not include costs associated with follow-up procedures; however, our analysis provides insight into the perioperative hospital costs and readmissions at 30 and 60 days. Third, this was a single institution study and so the results may not be generalizable to other settings. Lastly, we examined cases at the introduction of Greenlight PVP and so there may be a learning curve among physicians in terms of performing the procedure. As a result, we decided to exclude the first 10 cases of Greenlight PVP for each physician. Despite these limitations, we believe that this study contributes to improving our estimates of the marginal costs of Greenlight PVP, and essential clinical policy making. 


\section{Conclusion}

Greenlight PVP appears to be a safe and economically attractive option when compared to bipolar TURP and TURP. The procedure costs and readmission rates are lower for Greenlight PVP making it a preferable option for the hospital.

\section{References}

1. Wei JT, Calhoun E, Jacobsen SJ. Urologic Diseases in America Project: Benign Prostatic Hyperplasia. J Urol. 2008;179:S5.

2. Kapoor A. Benign prostatic hyperplasia (BPH) management in the primary care setting. Can J Urol. 2012;19:S1.

3. Reich O, Gratzke C, Bachmann A, et al. Morbidity, Mortality and Early Outcome of Transurethral Resection of the Prostate: A Prospective Multicenter Evaluation of 10,654 Patients. J Urol. 2008;180:246-249.

4. Bachmann A. Editorial comment on: transurethral photoselective vaporization versus transvesical open enucleation for prostatic adenomas $>80 \mathrm{ml}$ : 12 -mo results of a randomized prospective study. Eur Urol. 2008;54:435-436.

5. Bachmann A, Schürch L, Ruszat R, et al. Photoselective vaporization (PVP) versus transurethral resection of the prostate (TURP): A prospective bi-centre study of perioperative morbidity and early functional outcome. Eur Urol. 2005;48:965-972.

6. Stafinski T, Menon D, Harris K, Md GG, Jhangri G. Photoselective vaporization of the prostate for the treatment of benign prostatic hyperplasia. Can Urol Assoc J. 2008;2:124-134.

7. Stovsky MD, Griffiths RI, Duff SB. A clinical outcomes and cost analysis comparing photoselective vaporization of the prostate to alternative minimally invasive therapies and transurethral prostate resection for the treatment of benign prostatic hyperplasia. J Urol. 2006;176:1500-1506.

8. Goh AC, Gonzalez RR. Photoselective Laser Vaporization Prostatectomy Versus Transurethral Prostate Resection: A Cost Analysis. J Urol. 2010;183:1469-1473.

9. Liatsikos E, Kyriazis I, Kallidonis P, Sakellaropoulos G, Maniadakis N. Photoselective GreenLight ${ }^{\mathrm{TM}}$ Laser Vaporization Versus Transurethral Resection of the Prostate in Greece: A Comparative Cost Analysis. J Endourol. 2012;26:168173.

10. Whelan JP, Bowen JM, Burke N, et al. A prospective trial of GreenLight PVP (HPS120) versus transurethral resection of the prostate in the treatment of lower urinary tract symptoms in Ontario, Canada. J Can Urol Assoc. 2013;7:335-341.

11. Whitty JA, Crosland P, Hewson K, et al. A cost-minimisation analysis comparing 
photoselective vaporisation (PVP) and transurethral resection of the prostate (TURP) for the management of symptomatic benign prostatic hyperplasia (BPH) in Queensland, Australia. BJU Int. 2014;113:21-28.

12. Zhou Y, Xue B, Mohammad NA, et al. Greenlight high-performance system (HPS) 120-W laser vaporization versus transurethral resection of the prostate for the treatment of benign prostatic hyperplasia: a meta-analysis of the published results of randomized controlled trials. Lasers Med Sci. 2016;31:485-495.

13. Teng J, Zhang D, Li Y, et al. Photoselective vaporization with the green light laser vs transurethral resection of the prostate for treating benign prostate hyperplasia: A systematic review and meta-analysis. BJU Int. 2013;111:312-323.

14. Lukacs B, Loeffler J, Bruyre F, et al. Photoselective vaporization of the prostate with Greenlight 120-W laser compared with monopolar transurethral resection of the prostate: A multicenter randomized controlled trial. Eur Urol. 2012;61:11651173.

15. Capitán C, Blázquez C, Martin MD, Hernández V, De La Peña E, Llorente C. GreenLight HPS 120-W laser vaporization versus transurethral resection of the prostate for the treatment of lower urinary tract symptoms due to benign prostatic hyperplasia: A randomized clinical trial with 2-year follow-up. Eur Urol. 2011;60:734-739.

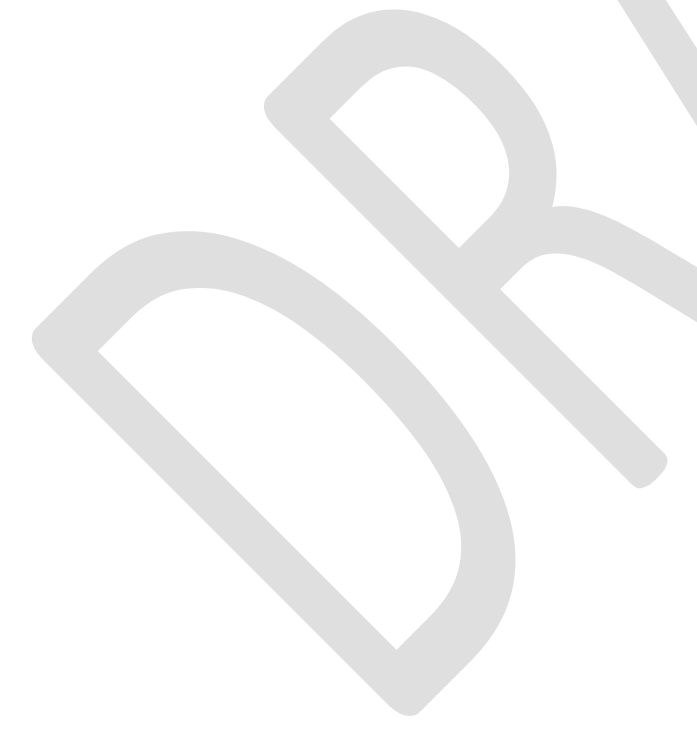


Figures and Tables

\begin{tabular}{|l|c|c|c|}
\hline \multicolumn{1}{|c|}{ Table 1. Patient characteristics and hospital data (n=203) } \\
\hline & $\begin{array}{c}\text { Greenlight } \\
\text { PVP } \\
\text { (n=56) }\end{array}$ & $\begin{array}{c}\text { Bipolar TURP } \\
\text { (n=29) }\end{array}$ & $\begin{array}{c}\text { TURP } \\
\text { (n=118) }\end{array}$ \\
\hline Age, years (SD) & $72(10)$ & $71(9)$ & $71(8)$ \\
\hline $\begin{array}{l}\text { Patients on anti-coagulation } \\
\text { therapy, n (\%) }\end{array}$ & $15(27)$ & $7(24)$ & $18(15)$ \\
\hline $\begin{array}{l}\text { Patients with past medical therapy } \\
\text { for BPH, n (\%) }\end{array}$ & $49(88)$ & $26(90)$ & $105(89)$ \\
\hline Prostate cancer, n (\%) & $5(9)$ & $0(0)$ & $8(7)$ \\
\hline Median lobe, n (\%) & $35(62 \%)$ & $54(46 \%)$ & $11(38 \%)$ \\
\hline Retention at time of surgery, n (\%) & $21(37 \%)$ & $42(36 \%)$ & $12(41 \%)$ \\
\hline Previous TURP, n (\%) & $6(11 \%)$ & $21(18 \%)$ & $5(17 \%)$ \\
\hline Charlson Comorbidity Index & $0.86(1.24)$ & $0.93(1.75)$ & $0.95(1.33)$ \\
\hline $\begin{array}{l}\text { No visits, n (\%) } \\
\text { Procedure completed as an }\end{array}$ & $52(93 \%)$ & $0(0 \%)$ & $7(6 \%)$ \\
outpatient & $4(7 \%)$ & $29(100 \%)$ & $111(94 \%)$ \\
$\begin{array}{l}\text { Procedure completed as an } \\
\text { inpatient }\end{array}$ & & & \\
\hline Inpatient length of stay, days & $1.03(0.27)$ & $1.45(0.57)$ & $1.67(0.56)$ \\
\hline Distance to clinic, km & $18.81(27.87)$ & $11.11(10.21)$ & $28.10(92.73)$ \\
\hline OR time in hours, mean (SD) & $1.30(0.54)$ & $1.18(0.38)$ & $1.09(0.40)$ \\
\hline $\begin{array}{l}\text { Number of laser fibre } \\
\text { Laser fibre=1 N (\%) }\end{array}$ & $55(98 \%)$ & & 0 \\
Laser fibre=2 N (\%) & $1(2 \%)$ & 0 & 0 \\
\hline
\end{tabular}

Data are presented as mean (SD) unless otherwise indicated. BPH: benign prostatic hyperplasia; OR: operating room; PVP: photoselective vaporization of the prostate; SD: standard deviation; TURP: transurethral resection of the prostate. 


\begin{tabular}{|c|c|c|c|c|c|}
\hline \multirow[t]{2}{*}{ Variable } & \multicolumn{3}{|c|}{ Mean $(95 \%$ CI) (\$) } & \multicolumn{2}{|c|}{ Difference in cost ${ }^{*}$} \\
\hline & $\begin{array}{l}\text { Greenlight } \\
\text { PVP n=56 }\end{array}$ & $\begin{array}{c}\text { Bipolar } \\
\text { TURP } \\
\text { n=29 }\end{array}$ & $\begin{array}{l}\text { TURP } \\
\mathrm{n}=118\end{array}$ & $\begin{array}{l}\text { (Greenlight- } \\
\text { TURP) }\end{array}$ & $\begin{array}{c}\text { (Greenlight- } \\
\text { bipolar TURP) }\end{array}$ \\
\hline \multicolumn{6}{|l|}{ Variable direct } \\
\hline Labour & 847 (722-922) & $\begin{array}{c}1767 \\
(1492-2041)\end{array}$ & $\begin{array}{c}1651 \\
(1536-1766)\end{array}$ & (804) & (920) \\
\hline $\begin{array}{l}\text { Patient } \\
\text { supplies }\end{array}$ & $\begin{array}{c}1,600 \\
(1456-1744)\end{array}$ & $\begin{array}{c}1093 \\
(888-1299)\end{array}$ & $\begin{array}{c}1098 \\
(1030-1166)\end{array}$ & 502 & 507 \\
\hline Other & $1(0.35-3.08)$ & $\begin{array}{c}11 \\
(8.75-14.17)\end{array}$ & $10(9-12)$ & (9) & (10) \\
\hline \multicolumn{6}{|l|}{ Fixed direct } \\
\hline Labour & 145 (128-162) & $\begin{array}{c}319 \\
(269-370)\end{array}$ & $\begin{array}{c}319 \\
(297-341)\end{array}$ & (174) & (174) \\
\hline Other & 147 (130-165) & $\begin{array}{c}194 \\
(168-220)\end{array}$ & $\begin{array}{c}209 \\
(198-220)\end{array}$ & (62) & (47) \\
\hline $\begin{array}{l}\text { Variable } \\
\text { indirect }\end{array}$ & 720 (655-785) & $\begin{array}{c}1108 \\
(957-1259)\end{array}$ & $\begin{array}{c}1125 \\
(1061-1188)\end{array}$ & $(405)$ & (388) \\
\hline Fixed indirect & 376 (335-418) & $\begin{array}{c}486 \\
(423-549)\end{array}$ & $\begin{array}{c}551 \\
(524-579)\end{array}$ & (175) & (110) \\
\hline Total cost & $\begin{array}{c}3836 \\
(3538-4137)\end{array}$ & $\begin{array}{c}4978 \\
(4321-5637)\end{array}$ & $\begin{array}{c}4963 \\
(4701-5226)\end{array}$ & $(1,127)$ & $(1,142)$ \\
\hline
\end{tabular}

*Brackets indicate that Greenlight is less costly. Costs do not include cost of readmission. Variable direct: cost of labour (medical personnel on fee for service), patient supplies, and drugs; fixed direct cost of labour (medical personnel not paid through fee for service) and equipment, building and grounds; variable and fixed indirect: hospital operating costs (i.e., functional centre costs classified as overhead). CI: confidence interval; PVP: photoselective vaporization of the prostate; TURP: transurethral resection of the prostate. 


\begin{tabular}{|l|c|c|c|}
\hline \multicolumn{4}{|c|}{ Table 3. Mean cost per patient per procedure for day surgery cases only } \\
\hline \multicolumn{1}{|c|}{ Variable } & $\begin{array}{c}\text { Mean Costs (95\% CI) (\$) } \\
\text { n=52 }\end{array}$ & $\begin{array}{c}\text { TURP } \\
\text { n=7 }\end{array}$ & $\begin{array}{c}\text { Difference in cost } \\
\text { (Greenlight- } \\
\text { TURP) }\end{array}$ \\
\hline Variable direct & & & \\
\hline Labour & $803(740-866)$ & $510(339-681)$ & 293 \\
\hline Patient supplies & $1583(1429-1737)$ & $997(654-1339)$ & 586 \\
\hline Other & $0.24(0.11-0.36)$ & $0.25(0.18-0.68)$ & $(0.01)$ \\
\hline Fixed direct & & & \\
\hline Labour & $133(122-144)$ & $82(40-125)$ & 51 \\
\hline Other & $141(124-158)$ & $140(93-185)$ & 2 \\
\hline Variable indirect & $691(631-752)$ & $600(432-769)$ & 91 \\
\hline Fixed indirect & $362(324-400)$ & $343(236-451)$ & 19 \\
\hline Total cost & $3713(3420-4006)$ & $2672(1776-3568)$ & 1,041 \\
\hline
\end{tabular}

*Brackets indicate Greenlight is less costly. Costs do not include cost of readmission. Variable direct: cost of labour (medical personnel on fee for service), patient supplies, and drugs; fixed direct cost of labour (medical personnel not paid through fee for service) and equipment, building and grounds; variable and fixed indirect: hospital operating costs (i.e., functional centre costs classified as overhead). CI: confidence interval; PVP:

photoselective vaporization of the prostate; TURP: transurethral resection of the prostate. 


\begin{tabular}{|c|c|c|c|c|c|}
\hline \multirow[b]{2}{*}{ Variable } & \multicolumn{3}{|c|}{ Mean $(95 \%$ CI) (\$) } & \multicolumn{2}{|c|}{ Difference in cost* } \\
\hline & $\begin{array}{c}\text { Greenlight } \\
\text { PVP } \\
\text { n=4 }\end{array}$ & $\begin{array}{c}\text { Bipolar } \\
\text { TURP } \\
\mathbf{n}=29\end{array}$ & $\begin{array}{l}\text { TURP } \\
\mathbf{n}=111\end{array}$ & $\begin{array}{c}\text { (Greenlight- } \\
\text { TURP) }\end{array}$ & $\begin{array}{c}\text { (Greenlight- } \\
\text { bipolar } \\
\text { TURP) }\end{array}$ \\
\hline Variable direct & & & 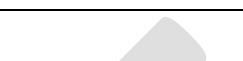 & & \\
\hline Labour & $\begin{array}{c}1425 \\
(1055-1796)\end{array}$ & $\begin{array}{c}1767 \\
(1491-2042)\end{array}$ & $\begin{array}{c}1723 \\
(1614-1832)\end{array}$ & (298) & (342) \\
\hline $\begin{array}{l}\text { Patient } \\
\text { supplies }\end{array}$ & $\begin{array}{c}1824 \\
(1699-1949)\end{array}$ & $\begin{array}{c}1093 \\
(888-1299)\end{array}$ & $\begin{array}{c}1104 \\
(1034-1174)\end{array}$ & 720 & 731 \\
\hline Other & $16(5-37)$ & $11(9-14)$ & $\begin{array}{c}11 \\
(10-13)\end{array}$ & 5 & 5 \\
\hline Fixed direct & & & 2 & 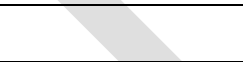 & \\
\hline Labour & $\begin{array}{c}299 \\
(162-436) \\
\end{array}$ & $\begin{array}{c}319 \\
(269-370) \\
\end{array}$ & $\begin{array}{c}334 \\
(314-354) \\
\end{array}$ & (35) & (20) \\
\hline Other & $233(142-324$ & $\begin{array}{c}194 \\
(157-220)\end{array}$ & $\begin{array}{c}213 \\
(202-224)\end{array}$ & 20 & 39 \\
\hline $\begin{array}{l}\text { Variable } \\
\text { indirect }\end{array}$ & $\begin{array}{c}1094 \\
(779-1408)\end{array}$ & $\begin{array}{c}1108 \\
(957-1259)\end{array}$ & $\begin{array}{c}1158 \\
(1096-1220)\end{array}$ & (64) & (15) \\
\hline Fixed indirect & $\begin{array}{c}562 \\
(287-838)\end{array}$ & $\begin{array}{c}486 \\
(423-549)\end{array}$ & $\begin{array}{c}566 \\
(538-592)\end{array}$ & (2) & 76 \\
\hline Total cost & $\begin{array}{c}5453 \\
(4512-6395)\end{array}$ & $\begin{array}{c}4978 \\
(4321-5637)\end{array}$ & $\begin{array}{c}5109 \\
(4856-5360)\end{array}$ & 344 & 475 \\
\hline
\end{tabular}

*Brackets indicate Greenlight is less costly. Costs do not include cost of readmission. Variable direct: cost of labour (medical personnel on fee for service), patient supplies, and drugs; fixed direct cost of labor (medical personnel not paid through fee for service) and equipment, building and grounds; variable and fixed indirect: hospital operating costs (i.e., functional centre costs classified as overhead). CI: confidence interval; PVP: photoselective vaporization of the prostate; SD: standard deviation; TURP: transurethral resection of the prostate. 


\begin{tabular}{|l|c|c|c|}
\hline \multicolumn{1}{|c|}{ Table 5. Readmission costs at 30 and 60 days } \\
\hline \multicolumn{1}{|c|}{ Variable } & Greenlight PVP & Bipolar TURP & TURP \\
\hline Total readmissions, $\mathrm{n}(\%)$ & $8(14)$ & $8(28)$ & $27(23)$ \\
\hline $\begin{array}{l}\text { Readmission at 30 days, } \mathrm{n} \\
(\%)\end{array}$ & $8(14)$ & $8(28)$ & $23(19)$ \\
\hline $\begin{array}{l}\text { Total cost of readmission } \\
\text { at } 30 \text { days, mean (SD) }\end{array}$ & $\$ 359(\$ 236)$ & $\$ 225(\$ 96)$ & $\$ 383(\$ 419)$ \\
\hline $\begin{array}{l}\text { Readmission at 60 days, } \mathrm{n} \\
(\%)\end{array}$ & $0(0)$ & $0(0)$ & $4(4)$ \\
\hline $\begin{array}{l}\text { Total cost of readmission } \\
\text { at } 60 \text { days, mean (SD) }\end{array}$ & 0 & 0 & $\$ 2460(\$ 3811)$ \\
\hline
\end{tabular}

PVP: photoselective vaporization of the prostate; SD: standard deviation; TURP: transurethral resection of the prostate.

\begin{tabular}{|l|c|c|}
\hline \multicolumn{3}{|l|}{ Table 6. Predictors of total cost (initial procedure + readmissions) } \\
\hline Variable & Coefficient (95\% CI) & p \\
\hline $\begin{array}{l}\text { Procedure vs. Greenlight PVP } \\
\text { (reference) }\end{array}$ & & \\
\hline TURP & $1219(732,1707)$ & $<0.01$ \\
\hline Bipolar TURP & $1156(170,1843)$ & 0.01 \\
\hline Age & $-11.73(-37,13)$ & 0.360 \\
\hline Charlson Comorbidity Index $>2$ & $769(93,1445)$ & 0.026 \\
\hline Distance to clinic, km & $0.36(-2.59,3.31)$ & 0.812 \\
\hline
\end{tabular}

CI: confidence interval; PVP: photoselective vaporization of the prostate; TURP: transurethral resection of the prostate. 